ReVista del Posgrado en DEREcho de la unAM

NuEVA ÉPOCA, AÑo 4, NúM. 7, JuLIO - Diciembre 2017

\title{
EL SEMIPRESIDENCIALISMO: ¿UNA ALTERNATIVA PARA EL SISTEMA POLÍTICO MEXICANO?
}

\author{
SEMI-PRESIDENTIALISM: AN ALTERNATIVE FOR THE MEXICAN \\ POLITICAL SYSTEM?
}

Gustavo EduARDo CAstañeda CAMACHO'

RESUMEN: Los sistemas parlamentario y presidencial son formas de gobierno dentro de los regímenes políticos democráticos. Lo que hace especial a estos sistemas, es que son los diseños más influyentes en el mundo moderno occidental, aunque no son los únicos. México se encuentra en los preludios de una transición de gobierno que se presenta ambivalente ante sus gobernados, al despertar sentimientos opuestos en la misma ciudadanía. Las expectaciones respecto a este vaivén, oscilan en un cúmulo de variables que en el cas d'espèce se tornan insondables en temas político-constitucionales. Una gran incógnita es concierne al sistema de gobierno, en el que la disyuntiva abre el debate lego y académico para dilucidar qué régimen político sería más conveniente para nuestro país: ¿el presidencialismo, el parlamentarismo o acaso el semipresidencialismo?

Palabras Clave: Semipresidencialismo, presidencialismo, parlamentarismo, regímenes democráticos, $V$ República francesa.

ABstraCt: Parliamentary and presidential systems are forms of government within democratic political regimen. What makes these systems special is that they are the most influential designs in the modern Western world, even though they are not the only ones. Mexico is in the prelude of a transition of government that is ambivalent before its governed, and its awaking opposing feelings in the citizens. The expectations regarding this oscillate in a cluster of variables that in the cas d'espèce become unfathomable in political-constitutional issues. A big question in the government system, in which the dilemma opens a lego and academic debate to elucidate which political regimen would be more convenient for our country: presidentialism, parliamentarism? Or perhaps semi-presidentialism?.

${ }^{1}$ Profesor de la Facultad de Derecho de la UNAM. Maestro en Derecho por la UNAM. Ha realizado estudios en la Universidad del Rosario en Colombia, Universidad Complutense de Madrid y Universidad Autónoma de Madrid. Profesor visitante en el Instituto Internacional de Sociología Jurídica de Oñati, País Vasco. 
KEYWORDS: Semi-presidentialism, presidentialism, parliamentarism, democratic regimen, French Fifth Republic.

SumARIO: I. Planteamiento; II. ¿Por qué semipresidencialismo y no semiparlamentarismo?; III. Arquetipos de regímenes semipresidenciales; IV . El prototipo de la V República (el semipresidencialismo en Francia); V. Consideraciones finales; VI. Fuentes.

\section{PlanteAMIENTO}

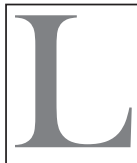

a estructura política de nuestro mundo está construida a través de comunidades sociales, integradas por un pueblo, territorio y poder, a las cuales denominados Estados ${ }^{2}$. Actualmente hay aproximadamente 190 Estados miembros de la Organización de las Naciones Unidas, aunque hay otros que no forman parte de esta asociación de gobierno global ${ }^{3}$. Cada Estado tiene distintas instituciones políticas, regímenes y sistemas que se encargan de gobernar. Así, dentro de los regímenes políticos democráticos

\footnotetext{
${ }^{2}$ En este sentido nos dice Acosta Romero: "Desde la más remota antigüedad se ha reconocido al hombre agrupado, actuando aún frente a la naturaleza, por medio de los grupos más primitivos, en los cuales, necesariamente hubo cierta organización y ciertos principios de orden. La historia recoge las primeras formaciones sociales permanentes en Egipto, cerca del año 6000 a.C., y es a partir de entonces que, cuando se conoce como polis, ciudad, imperio, república, a la agrupación humana asentada en un territorio con un cierto orden y una determinada actividad y fines.” Acosta Romero, Miguel, Teoría general del Derecho administrativo, México, Porrúa,1981, p. 35.

${ }^{3}$ Según la Carta de las naciones unidas, de 1945, capítulo II, artículo 3: "Son Miembros originarios de las Naciones Unidas los Estados que habiendo participado en la Conferencia de las Naciones Unidas sobre Organización Internacional celebrada en San Francisco, o que habiendo firmado previamente la Declaración de las Naciones Unidas de 1 de enero de 1942, suscriban esta Carta y la ratifiquen de conformidad con el Artículo 110"; no obstante que no se tratase estados miembros originarios, podrán integrarse a la ONU: "...todos los demás Estados amantes de la paz que acepten las obligaciones consignadas en esta Carta, y que, a juicio de la Organización, estén capacitados para cumplir dichas obligaciones y se hallen dispuestos a hacerlo...”; según el tenor del artículo 4, del antes aludido documento. (Cfr. Seara Vázquez, Modesto, Las naciones unidas a los cincuenta años, México, FCE, 1995, p.12)
} 
encontramos dos grandes sistemas ${ }^{4}$ : el parlamentarismo ${ }^{5}$ y el presidencialismo $^{6}$. Lo que hace especiales a estos sistemas, es que en el mundo occidental, son los diseños más influyentes. Sin embargo, la historia contemporánea nos ha mostrado que ambos sistemas presentan defectos ${ }^{7}$, especialmente en sus formatos más ortodoxos.

${ }^{4}$ Jorge Reis Novais, catedrático de Derecho de la Universidad de Lisboa, nos dice con relación a estos dos sistemas: "Durante muito tempo, presidencialismo e sistema parlamentar repartiram em exclusividade e domínio dos sistemas de governo adoptados pelas diferentes democracias representativas: sistema parlamentar na Europa e presidencialismo na América, tendo, como respectivos paradigmas, o Reino Unido e os Estados Unidos da America”. (Reis, Novais, Jorge, Semipresidencialismo, teoría do sistema de governo semipresidencial, Portugal, Almedina, 2007, p. 59).

${ }^{5}$ A reserva de la caracterización ulterior que efectuaremos sobre el parlamentarismo, no nos resistimos a hacer patente la que al respecto del mismo efectua el catedrático de liboa, en el capítulo II, del primer volumen, perteneciente a la obra citada: "Sistema parlamentar é aquele em que o Governo (o executivo) é politicamente responsável perante o Parlamento, isto é, a subsistencia do executivo depende da confiança política do Parlamento, e em que $o$ chefe do Estado, não sendo eleito, não pode exercer efectivamente poderes políticos. Nesse sistema há, portanto dois pólos de excercício de poder político: o Governo, liderado por um Primeiro-Ministro, e um Parlamento." (Reis, Novais, Jorge, op.,cit.,p. 64)

6 Aunque ya es común esta distribución bipartita de los sistemas políticos democráticos, el presidencialismo no es del todo un sistema original y virtuoso, ni se da tampoco a lo largo de todo el mundo con dichas características; pues es en américa latina donde se ha podido observar en principio como tal. Con palabras diáfanas nos ilustra al respecto, Duverger, finado catedrático de la Universidad de Burdeos: "El presidencialismo constituye una aplicación deformada del régimen presidencial clásico, por debilitamiento de los poderes del Parlamento e hipertrofia de los poderes del presidente: de ahí su nombre. Funciona sobre todo en los países latinoamericanos que han transportado las instituciones constitucionales de los Estados Unidos a una sociedad diferente, caracterizada por el subdesarrollo técnico, el predominio agrario, las grandes propiedades agrícolas y la semicolonialización por la vecina y superpoderosa economía de los Estados Unidos” (Duverger, Maurice; Instituciones políticas y derecho constitucional, Barcelona, Ariel, 1984, p.152.)

${ }^{7}$ Sirvan a manera de ejemplo, las desventajas que apuntan Ebrad Casaubon y Robles Villaseñor, en Semipresidencialismo en México, ¿salida al estancamiento del régimen?', Introducción, p., 17: "Dada la separación de poderes del régimen presidencialista resulta relevante la integración de Congreso en relación con el partido del que provenga el presidente. Si este partido tiene la mayoría en el poder legislativo, es muy probable que se establezca una relación de colaboración entre ambos poderes y que el plan de gobierno y las políticas públicas del titular del poder ejecutivo sean respaldadas desde el congreso. En cambio, si el partido del presidente no logra la mayoría absoluta en el Congreso, entonces se tendrá una situación conocida como "gobierno dividido". Aun con un gobierno dividido, es decir, cuando un partido de oposición o una alianza de partidos de oposición tiene mayoría en el Congreso, es posible que existan acuerdos que lleven a la colaboración entre poderes, pero también es altamente probable que la colaboración sea desplazada para dar paso a la confrontación, o cuando menos, al bloqueo mutuo y el congestionamiento, tanto de las labores legislativas, como las propias 
Como caras opuestas de una moneda, el parlamentarismo y el presidencialismo aparentan ser posturas diametralmente incompatibles. Es a raíz de estos extremos que nace la inquietud por buscar alguna alternativa, una solución sintética que ocupe las virtudes y deseche las fallas. Ante esta cuestión la respuesta más obvia propone la configuración de un sistema "ecléctico", que recibe el nombre de semipresidencialismo. Por ello, en el presente trabajo efectuaremos una aproximación teórica al modelo del semipresidencialismo, particularmente desde el prototipo francés, revisando sus antecedentes y estudiando su sistema político actual. Además, examinaremos los casos cercanos y lejanos al arquetipo galo. Finalmente, arribaremos a nuestras conclusiones, en las que se verificará o no, si el semipresidencialismo constituye una verdadera alternativa como sistema para los regímenes democráticos.

\section{II. ¿POR QUÉ SEMIPRESIDENCIALISMO Y NO SEMIPAR-}

\section{LAMENTARISMO?}

Ya hemos dicho que el sistema que intenta combinar elementos del presidencialismo y parlamentarismo se denomina semipresidencialismo $^{8}$, de ahí que una de las primeras preguntas que nos vengan a la mente sea: ¿por qué semipresidencialismo y no semiparlamentarismo 9 ? Prima facie, el nombre nos indica que hay una cierta pre-

del gobierno, en perjuicio finalmente, de la población gobernada.” (Ebrad, Casaubón, Marcelo y Robles, Villaseñor, Mara, Semipresidencialismo en México, ¿salida al estancamiento del régimen?, México, Escuela de Administración Pública del Distrito Federal, 2011, p. 17)

${ }^{8}$ A efecto de auxiliarnos en nuestra ulterior caracterización del semipresidencialismo, introducimos aquí la noción del mismo, que aporta el profesor de la Universidad de Lisboa, Jorge Reis Novais: "Semipresidencialismo é o sistema de governo de democracia representativa que junta as seguintes características: há um Presidente eleito por sufragio popular e que pode exercer poderes constitucionais significativos e há um Governo políticamente resposável perante o Parlamento.” (Reis, Novais, Jorge, op., cit., p. 141)

${ }^{9}$ Se atildará tal dubitación sobre todo si se considera que el parlamentarismo clásico como nos dice Duverger: “...el jefe del estado es, o un monarca hereditario, o un presidente designado por los parlamentarios y notables, uno y otro están más lejos de la soberanía popular que el primer ministro y tienen menos que él la calidad de repre- 
eminencia en el presidencialismo y que en todo caso el semipresidencialismo se descifra y edifica mejor desde la base del primero, ladeando en algún grado al parlamentarismo. Pero, ¿hasta qué punto el presidencialismo y el semipresidencialismo se asemejan? o ¿será acaso su denominación una simple coincidencia o una formulación académica veleidosa?

De entrada el primer denominador común que encontramos entre el presidencialismo y el semipresidencialismo, es que el presidente no es nombrado por el parlamento, ni es el líder del grupo parlamentario más aventajado, lo que significa que el mandatario surge de una elección popular ${ }^{10}$.

No obstante, estos dos sistemas se desvinculan drásticamente, empezando por el hecho de que en el semipresidencialismo el poder del titular del Ejecutivo, pasa de estar aislado en una persona a bifurcarse en un mando dual ${ }^{11}$.

Otra diferencia se halla en el apoyo y conservación que adquiere la figura del Ejecutivo, v. gr., en los sistemas presidenciales, el actor principal se encuentra protegido de una contingente injerencia del Poder Legislativo, debido al respeto que se le da al principio de la división de poderes. Mientras que en el sistema semipresidencialista el poder se ejerce de forma compartida entre el presidente y un primer ministro, y además este último necesita tener el soporte constante del parlamento.

En realidad, por extraño que parezca (y en contradicción a su nombre), el semipresidencialismo tiene más características en común con el régimen parlamentario que con el presidencialismo. ¿Por qué el semipresidencialismo se aproxima en mayor grado al parlamentarismo? Basta con enunciar los elementos fundamentales que el régimen parlamentario comparte con el semipresidencialis-

sentantes de la nación. Los poderes que la constitución les atribuye son nominales y ejercidos de hecho por el gobierno...” (Duverger, Maurice; op., cit., p. 153.)

10 Sartori, Giovanni; Ingeniería constitucional comparada, México, Fondo de Cultura Económica, 1994, p. 136.

11 Idem. 
mo, para disipar cualquier duda. En concreto, ambos sistemas:1) dividen el poder del Ejecutivo entre un jefe de Estado y un gabinete del que emerge un jefe de gobierno; 2) el gabinete es responsable políticamente ante el parlamento; 3) el parlamento tiene la capacidad de deponer al jefe de gobierno y a sus ministros a través de un voto de no confianza; y finalmente 4) el Ejecutivo cuenta con la prerrogativa de disolver el parlamento, lo que se traduce en influjos sobre éste ${ }^{12}$. Entonces, si el semipresidencialismo se asemeja más al parlamentarismo, ¿por qué la denominación de dicho sistema hace referencia al presidencialismo? Básicamente como se habíamos dicho en párrafos ut supra, porque el representante del Poder Ejecutivo es electo por sufragio universal, es decir, el jefe de Estado no es un monarca hereditario, ni tampoco se trata de un dirigente ungido por una junta de notables o los parlamentarios. ${ }^{13}$

En conclusión, no debemos asumir textualmente la denominación del sistema semipresidencial, ya que sus notas particulares convergen más con el parlamentarismo, pese a que no alcance a llamarse semiparlamentarismo. ${ }^{14}$

\section{ARQUETIPOS DE REGÍMENES SEMIPRESIDENCIALES}

Así como los sistemas parlamentario y presidencial tienen como casos paradigmáticos, el parlamento de Reino Unido y la presidencia de los Estados Unidos de América, el semipresidencialismo localiza su caso sobresaliente en la V República francesa.

\footnotetext{
${ }^{12}$ Duverger, Maurice, op. cit., p. 152

${ }^{13}$ Idem.

${ }^{14}$ El mismo Giovanni Sartori nos remite a dos teóricos, quienes apegados a consideraciones de tipo filológico, nos presentan un criterio distinto sobre la denominación del semipresidencialismo, cuyos criterios son expuestos por el constitucionalista Italiano mediante la ulterior paráfrasis: " en un planteamiento contrario reemplazan al semipresidencialismo argumentando que semi sugiere Dun tipo de régimen que está a la mitad de un continuum'. Pero semi es un prefijo de origen latino que significa "medio" (por ejemplo, semicírculo, mediocirculo, no en medio) y no supone ningún continuum como cualquier diccionario lo demuestra para cientos de expresiones, pues precedió por mucho al inicio de la manía del continuum."; apud Sartori, op., cit., p.137.
} 
Efectivamente, cuando queremos poner el ejemplo de un país con un sistema semipresidencial, el primero en el que pensamos es en el régimen instaurado en Francia en 1962 por medio de una reforma constitucional, con la que se estableció la elección popular del presidente de la república, sin que ello implicara soslayar el escenario parlamentario ${ }^{15}$. Pero, ¿ ¿fueron los franceses los primeros en aplicar el sistema semipresidencial? La respuesta es no, puesto que históricamente otros países lo han puesto en práctica, tales son los casos de la Alemania de Weimar y Austria.

A pesar de que son citables los ejemplos de regímenes semipresidenciales, los casos resultan atípicos. Algunos países que podemos "englobar" dentro de esta categoría son: Francia desde 1962, Austria, Finlandia, Portugal, Islandia, Irlanda, la Alemania de Weimar y Sri Lanka. Ponemos entrecomillado englobar, porque la disparidad de rasgos característicos de estos casos es considerable, lo que impide afirmar su pertenencia o no al semipresidencialismo. Por ejemplo, el caso de Irlanda que bien lo podríamos comprender dentro del sistema parlamentario ${ }^{16}$.

De hecho, si quisiéramos ser más precisos en la elaboración de un inventario de países semipresidenciales, tendríamos que acortar este primer registro. Empezando por retirar a los regímenes de Austria e Islandia, en vista de que sólo son semipresidenciales en la constitución, pero en la praxis se acercan más a un parlamentarismo clásico, pues el presidente es un símil de un jefe de Estado ornamental, sin mayor peso político. Algo similar sucede con Irlanda, a pesar de que el presidente es electo por sufragio universal.

En pocas palabras, en Austria, Irlanda e Islandia lo que prevalece es el ejercicio parlamentario, de modo que los presidentes se quedan como figuras que engalanan a sus Estados ${ }^{17}$.

\footnotetext{
${ }^{15}$ Ibidem, p. 152 .

${ }^{16}$ Cfr. Shugart, M. S. y Carey, J. M.; Presidents and Assemblies: Constitutional Design and Electoral Dynamics, Nueva York, Cambridge University Press, 1992.

17 Duverger, Maurice; "A new political system model: semi-presidential government”, en Fournal of political research, vol. 8, núm. 2, 1980, pp.165-187.
} 
Hasta aquí se podría objetar que hacer un catálogo restringido de países que se encuadran dentro del semipresidencialismo le resta importancia a este sistema, ya que la muestra pierde dimensión; sin embargo, para entender con mayor fidelidad lo qué es el semipresidencialismo, resulta necesario eliminar a los prototipos espurios. Con lo que tachamos de nuestra lista a Austria, Irlanda e Islandia. Quedándonos con una relación refinada de cinco países: Francia (1962); Alemania de Weimar; Finlandia; Portugal; y Sri Lanka. Como se mencionó en el primer párrafo de este apartado, la V República francesa es el caso por antonomasia del sistema semipresidencial, por lo que recibirá un tratamiento especial en la sección ulterior.

Hecha esta aclaración, empezaremos con la Alemania de Weimar, en vista de que sirve como referencia histórica. Evidentemente, en los albores del régimen político de Weimar, no pasaba por la cabeza de nadie el modelo semipresidencial. En consecuencia fue entendido como un sistema parlamentario mitigado por una dirigencia robusta ${ }^{18}$. Como ejemplo de esta presidencia fuerte, revisemos lo estipulado por el artículo 48 de la Constitución de Weimar.

Si un País no cumple los deberes que le impone la Constitución o las leyes del Imperio el Presidente de éste podrá obligarle a ello, con ayuda de la fuerza armada. Cuando se hayan alterado gravemente o estén en peligro la seguridad y el orden públicos en el Imperio, el Presidente puede adoptar las medidas indispensables para el restablecimiento de los mismos, incluso en caso necesario con ayuda de la fuerza armada. Con este fin puede suspender temporalmente en todo o en parte los derechos fundamentales fijados en los artículos 114, 115, 117, 118, 123, 124 y 153.

De la lectura de dicho artículo, observamos que la Constitución de Weimar le otorgaba al presidente la facultad para gobernar por decreto en situaciones de emergencia. Un permiso para nada menor.

${ }^{18}$ Sartori, Giovanni; Ingeniería constitucional comparada..., cit., 144. 
La experiencia semipresidencial de Weimar tuvo una vida breve, acabándose tras el golpe de la “Gran Depresión”, no obstante, nos dejó una obra constitucional notable y una prueba de lo que a la postre sería el semipresidencialismo. La caducidad de Weimar sólo permitió que hubiera dos elecciones presidenciales con voto popular, la primera vez en 1928 y la segunda en 1932, expirándose al siguiente año ${ }^{19}$.

Ahora pasemos al caso de Portugal, cuyo ejercicio semipresidencial se mantuvo apenas seis años, de 1976 a 1982. Inspirada en el prototipo francés, su desenlace no fue necesariamente similar, ya que la frustración de este proyecto se debió en gran medida a que el presidente no se benefició del apoyo político de algún partido. Aunado a ello, las mayorías fraccionadas que subsistieron en aquel régimen consiguieron fracturar los contrapesos que implica el semipresidencialismo $^{20}$.

Prosigamos nuestro análisis con Sri Lanka, país que al igual que Portugal siguieron el ejemplo francés, aunque con ciertas particularidades, ya que en la Constitución de 1978 se fortificó la potestad del presidente, aproximándose a la configuración hecha por Weimar. En este caso, el presidente de Sri Lanka, asimilándose al de Weimar, detenta un poder unilateral y discrecional, con el que puede influir en la aprobación por referéndum de las leyes censuradas por el parlamento. No sólo el modelo semipresidencial de Sri Lanka dotó de mayores facultades al presidente, en razón de lo presentado en la $\mathrm{V}$ República y en Weimar, sino que fue más allá del paradigma tradicional del semipresidencialismo al fusionar en la persona del presidente al jefe de Estado y al jefe de gobierno. Esto significa que en la práctica el presidente elige a sus ministros y emite propuestas de ley, prerrogativas análogas al sistema presidencial.

\footnotetext{
${ }^{19}$ Duverger, Maurice; Instituciones politicas y derecho constitucional..., cit., p. 154.

${ }^{20}$ Sartori, Giovanni; Ingeniería constitucional comparada..., cit., p. 146.
} 
Considerando esta exposición de la figura del presidente en Sri Lanka, muchos opinaran que se trata más bien de un régimen presidencial puro; sin embargo, hay una característica que persiste en inclinar la balanza por el sistema semipresidencial. Se trata del voto de censura que tiene el parlamento para destituir al gabinete, con lo que se demuestra la falta de separación de poderes, que define al presidencialismo $^{21}$.

Para finalizar con esta comparación de arquetipos de regímenes semipresidenciales, examinemos el caso de Finlandia, que no por ser el último de la lista es el más reciente, pues, de hecho, es el más antiguo junto a Weimar, dado que su origen estuvo en 1919. El formato finlandés, a diferencia de Sri Lanka, se parece más a un sistema parlamentario, en vista de que el parlamento escoge y cesa a los gobiernos. Aunque el presidente no queda desprovisto de atribuciones, puesto que nombra al primer ministro y conduce las reuniones del gabinete de interés internacional, no así de los asuntos domésticos.

En conclusión, podemos señalar que los modelos de semipresidencialismo se manifiestan abigarrados y dispares, de tal suerte que descubrir casos idénticos resulta una tarea irrealizable y por demás estéril. En todo caso, lo que se percibe es que el prototipo ofrecido por la V República francesa, es el ideal al que han aspirado otros ensayos del semipresidencialismo.

\section{EL PROTOTIPO DE LA V REPÚBLICA (EL SEMIPRESI- DENCIALISMO EN FRANCIA)}

Indiscutiblemente, el prototipo de la V República francesa es el modelo a seguir de los otros sistemas semipresidenciales, por lo que se hace ineludible detenernos a examinar la propuesta gala.

\footnotetext{
${ }^{21}$ Ibidem, p. 147.
} 


\section{EXTINGUIENDO EL ANCIEN RÉGIME}

Comencemos con los antecedentes de este sistema político. Así, si quisiéramos poner una fecha de su arranque, diríamos que es 1789. Porque es el año en el que se le pone fin al ancien régime, para entrar a la política moderna. La Revolución francesa tuvo su origen, precisamente en un tema de gobierno, pues mientras la ideología liberal y la burguesía evolucionaban, la monarquía se quedó estática, conservando un aparato real ostentoso e inservible (elementos comunes de las monarquías dieciochescas). Las consecuencias de la revolución fueron diversas, no sólo consumió al antiguo régimen, sino que desató la disensión nacional, pensemos por ejemplo en la falta de acuerdo para la determinación de la forma de gobierno francés después de la cese de la monarquía. Esta condición histórica llevó a Francia durante los siglos XIX y XX a buscar un régimen que fuera aprobado por la mayoría de los franceses ${ }^{22}$. Los experimentos del gobierno francés, pasaron por la I República; el Primer Imperio bajo el control de Napoleón Bonaparte; la reinstauración de la monarquía con la casa de los Borbones; la monarquía de la casa de Orleans; la II República; el Segundo Imperio con Napoleón III; la III República; la IV República, iniciada después de la Segunda Guerra Mundial; para finalmente en 1958 establecer la actual V República, apoyada en un presidente fuerte como lo fue Charles de Gaulle. Durante esta serie de ensayos, sobresale el asentamiento de la república parlamentaria, la cual estuvo vigente casi un siglo, pese a que en 1920 el parlamentarismo se deterioró. Como se puede advertir, después de 1789 la política en Francia ha sido dinámica, siempre en busca del mejor gobierno para su pueblo. Aunque, es posible identificar dos grandes fases, la primera de 1789 a 1875 , período en el que los gobiernos se mostraron inconsistentes, en el que se transitaba de monarquía a imperio y de éste a república, sin mayor disimulo. Y una segunda época que va de 1875 hasta 1958, con el fin del Segun-

${ }^{22}$ Duverger, Maurice; Instituciones políticas y derecho constitucional... cit., p. 272. 
do Imperio francés y la admisión de la república (curiosamente de la parlamentaria).

A pesar de que en la primera fase, se observa un relevante vaivén político, en realidad la inestabilidad fue más aparente que efectiva, ya que los regímenes que estuvieron en vigor durante este intervalo de tiempo son semejantes. Tomemos en cuenta que Francia en este lapso osciló entre la monarquía parlamentaria, la monarquía republicana, y la república presidencial. Sumado a ello, cabe señalar que los dos primeros sistemas ocuparon la mayor parte del tiempo de este primer período.

Al término del Segundo Imperio, el sistema político que se alzó para tomar las riendas de Francia fue la república, creándose instituciones sólidas, pues de hecho, la III y IV República se prolongaron todo esta segunda fase, no obstante, la estabilidad del sistema, no se tradujo en una firmeza gubernativa. Encontramos en esta etapa dos constituciones: la "Constitución de 1875 " 23 y la Constitución de 1946. La primera estableció un parlamentarismo clásico y la segunda intentó mantenerlo, pero los problemas sociales, la posguerra y la Crisis de Mayo, propiciaron el declive del parlamentarismo y de la IV República ${ }^{24}$.

2. LOS ALBORES DE LA V REPÚBLICA Y DEL SEMIPRESIDENCIALISMO

Una vez estudiados los antecedentes políticos del régimen semipresidencial en Francia, avancemos nuestra investigación con la V República y su sistema actual. El sistema político conocido como la V República francesa procede de la Constitución de 1958, la cual tuvo su origen tras el regreso al poder de Charles de Gaulle. Recordemos que la Asamblea Nacional consintió que el nuevo jefe de gobierno

${ }^{23}$ La Constitución de 1875, no es propiamente una constitución, pues el ala monárquica de la Asamblea Nacional no permitió que se plasmase el republicanismo en un documento oficial; sin embargo, se promulgaron tres leyes, las cuales conformaron lo que se conoce como la Constitución de 1875.

${ }^{24}$ Ibidem, p. 275. 
pudiera elaborar una constitución, siempre y cuando fuera ratificada por la nación. Así, el 28 de septiembre de 1958 fue adoptada por referéndum ${ }^{25}$ la nueva constitución, siendo el decimoquinto texto fundamental de Francia.

La Constitución francesa de 1958 fue elaborada con el propósito de acabar con la inestabilidad en el gobierno y la guerra en Argelia. Como norma suprema del sistema jurídico, en primera instancia instauró un régimen parlamentario, aunque se caracteriza por confeccionar un Ejecutivo fuerte. El 6 de noviembre de 1962, una reforma constitucional transformó ampliamente el sistema trazado en 1958. El cambio se daba en la forma de elección del presidente de la república, pues de ser nombrado por un colegio de notables, pasaba a ser designado por votación popular. Esta modificación que en apariencia es nimia, le otorgó al Ejecutivo un gran poder. Previo a esta reforma el presidente era más bien un jefe de Estado parlamentario, sin autoridad. Tras el cambio constitucional, el Ejecutivo se torna en un jefe de gobierno con ejercicio real de sus funciones.

Lo referido hasta aquí pone de manifiesto, que, con la reforma constitucional de 1962, Francia abandonaba el parlamentarismo para establecer un régimen semipresidencial en stricto sensu. El prototipo que germinó fue inédito, ya que el presidente al ser electo por sufragio universal, detentaba una notable autoridad, pero no omnímoda, y mucho menos dictatorial, en vista de que el poder se distribuyó en el primer ministro y su gabinete, al estilo del parlamentarismo clási$\mathrm{Co}^{26}$. Como era de esperarse, los partidarios del parlamentarismo se opusieron a la reforma de 1962; sin embargo, ésta fue ratificada por referéndum del 28 de octubre del mismo año.

Estos son los comienzos de un régimen democrático distinto a los modelos típicos representados en el presidencialismo y el parlamentarismo. Su nombre "semipresidencialismo" y su ascendencia "la V República francesa”.

\footnotetext{
${ }^{25} \mathrm{El}$ referéndum fue aprobado con 17. 668. 790 votos a favor en la metrópoli, 4.624.511 en contra y 4.016.614 abstenciones.

${ }^{26}$ Ibidem, p. 276.
} 
3. ELEMENTOS Y CARACTERISTICAS DEL RÉGIMEN SEMIPRESIDENCIAL FRANCÉS

Hemos visto cómo es que Francia a lo largo de su historia abandonó gradualmente las arcaicas instituciones del Ancien régime, para convertirse en lo que hoy conocemos como la V República, régimen que estableció el semipresidencialismo, modelo que sigue vigente en el país galo.

Llegados a este punto, es menester examinar los elementos y características esenciales de este régimen. El semipresidencialismo francés es un sistema político democrático, expresada por medio del referéndum (democracia semidirecta); y del voto de los ciudadanos, con el que eligen a los parlamentarios (democracia representativa), y al presidente (democracia directa). Pero, la actividad política de los ciudadanos, no sólo se ejerce a través de estas vías, pues los partidos políticos mantienen un papel importante en la vida pública.

El Parlamento francés (Parlement français) representa al Poder Legislativo. Se compone por dos cámaras: el Senado (Sénat) ${ }^{27}$ y por la Asamblea Nacional de Francia (Assemblée nationale française) ${ }^{28}$. El Senado se integra por $348^{29}$ cargos electos y se renueva fraccionadamente cada tres años en dos series. Mientras tanto, la Asamblea Nacional se conforma por $577^{30}$ diputados, designados cada cinco años. La elección del Senado es por medio de una votación indirecta, y la de la Asamblea Nacional es a través de sufragio universal directo.

${ }^{27}$ El Senado francés tiene su sede en el Palacio de Luxemburgo (Palais du Luxembourg).

${ }^{28}$ La Asamblea Nacional de Francia tiene su sede en el Palacio de Bourbon (Palais Bourbon)

${ }^{29}$ La repartición de los escaños se da de la siguiente manera: 326 para los departamentos metropolitanos y de ultramar (cada departamento tiene al menos un representante); 2 para la Polinesia Francesa; 2 para Nueva Caledonia; 2 para Mayotte; 1 para San Pedro y Miquelón; 1 para San Martín; 1 para San Bartolomé; 1 para Wallis y Futuna; y 12 para los franceses residentes en el extranjero.

${ }^{30}$ Los 577 escaños de los diputados se reparten de la siguiente manera: 556 para los departamentos franceses; 10 para las colectividades de ultramar; y 11 para los franceses establecidos en el extranjero. 
La integración y funciones del Parlamento francés se localizan en la Constitución del 4 de octubre de 1958, en el Título IV, denominado "Del Parlamento", en los artículos 24 a 33. A continuación veamos el artículo 24, en el que se estipula como estará integrado el Parlamento, su número de miembros, y su forma de elección.

ARTICLE 24. Le Parlement vote la loi. Il contrôle l'action du Gouvernement. Il évalue les politiques publiques. Il comprend l'Assemblée nationale et le Sénat. Les députés à l'Assemblée nationale, dont le nombre ne peut excéder cinq cent soixantedix-sept, sont élus au suffrage direct. Le Sénat, dont le nombre de membres ne peut excéder trois cent quarante-huit, est élu au suffrage indirect. Il assure la représentation des collectivités territoriales de la République. Les Français établis hors de France sont représentés à l'Assemblée nationale et au Sénat ${ }^{31}$.

Ahora veamos lo correspondiente a la figura del Ejecutivo. El presidente de la república tiene el encargo de velar por el respeto a la Constitución y asegurar el funcionamiento de los poderes públicos, así como la conservación del Estado francés. Huelga decir, que es el garante de la independencia e integridad nacional. Como se destacó en párrafos ut suptra, con la reforma de 6 de noviembre de 1962, el presidente es seleccionado de una votación popular para un mandato de cinco años ${ }^{32}$ (desde el referéndum del año 2000), al obtener la mayoría absoluta de votos emitidos. Sin embargo, el mecanismo no es tan sencillo, ya que en caso de no obtenerse dicha mayoría en primera vuelta, se procederá a una segunda vuelta, al decimocuarto día siguiente. Para la segunda vuelta, sólo se podrán presentar los dos candidatos con más votos de la primera vuelta. Las elecciones presidenciales se llevarán a cabo durante los veinte y treinta y cinco días antes del fin del mandato presidencial en ejercicio.

${ }^{31}$ La traducción de dicho precepto sería la siguiente: "El Parlamento votará la ley. Controlará la acción del Gobierno. Evaluará las políticas publicas. Estará compuesto por la Asamblea Nacional y el Senado. Los diputados en la Asamblea Nacional, cuyo número no podrá exceder de quinientos setenta y siete, serán elegidos por sufragio directo. El Senado cuyo número de miembros no podrá exceder de trescientos cuarenta y ocho, será elegido por sufragio indirecto. Asumirá la representación de las entidades territoriales de la República

32 Originalmente se contempló que el mandato del presidente durara siete años. 
Como se ha dicho el presidente en Francia es más influyente que el de los regímenes parlamentarios, sin llegar a tener los poderes otorgados por un sistema presidencial puro. Veamos porque es así. Las principales facultades del presidente francés son: 1) nombrar al Primer Ministro, al cual puede cesar, en caso de que presente su dimisión al gobierno; 2) nombrar y cesar a los demás miembros del gobierno, a propuesta del Primer Ministro; 3) presidir el Consejo de Ministros; 4) promulgar las leyes; 5) pedir al Parlamento una nueva deliberación sobre una ley; 6) someter a referéndum cualquier proyecto de ley que verse sobre la organización de los poderes públicos, reformas vinculadas a la política económica, social y medioambiental, o que formule la ratificación de un tratado internacional; 7) acordar con el Primer Ministro y con los presidentes de las Cámaras, la disolución de la Asamblea Nacional; 8) firmar las ordenanzas y los decretos discutidos en el Consejo de Ministros; 9) nombrar los cargos civiles y militares del Estado; 10) acreditar a los embajadores ante países extranjeros; 11) presidir los consejos y los comités de la defensa nacional; 12) ejercer poderes extraordinarios en caso de estado de excepción; y 13) gozar de prerrogativas de indulto.

La elección y funciones del presidente francés se encuentran en el Título II, llamado "Del Presidente de la República”, a partir del artículo 5 hasta el 19 y el 52 de la Constitución de 1958. Deseamos subrayar que el liderazgo del presidente no está plasmado con claridad y permanece atomizado en el texto fundamental. La dispersión de las facultades más importantes del presidente obedecen a que son de carácter contingente, y excepcionales. Sumado a ello, hay que destacar que sus prerrogativas no son de decisión, sino más bien para frenar, póngase por ejemplo las prerrogativas de disolución de la Asamblea Nacional (artículo 12) y el referéndum de leyes (artículo 11) ${ }^{33}$.

${ }^{33}$ Sartori, Giovanni; Ingeniería constitucional comparada... cit., p. 137. 


\section{CONSIDERACIONES FINALES}

${ }_{\mathrm{C}}$ Es el semipresidencialismo algo que verdaderamente represente una esperanza de perfeccionamiento del sistema político mexicano? ${ }_{\mathrm{C}}$ Podemos considerar que, a partir de un cierto texto constitucional, con las modificaciones orgánicas que él deba implicar para adaptarse a los rasgos generales que hemos caracterizado como semipresidencialistas, habrá de lograrse per se de manera misteriosa, la solución al malestar político, o expresándonos en palabras de cierta referencia bibliográfica de la que nos hemos servido, ser la salida al estancamiento del régimen? Cualquiera que sea nuestra respuesta a ello, nos dejará con idéntico grado de incertidumbre. Lo que sí podemos saber es que el conocimiento constitucional, a través de su literatura nos muestra la posibilidad de establecer previsiones sobre los efectos en las modificaciones del régimen político.

El estudio de los sistemas semipresidencialistas en marcha, al través de sus más granados paradigmas, puede permitirnos establecer un asomo sobre las probables consecuencias de su implementación en nuestro país. Algunos teóricos afirman que aún con las deficiencias de los sistemas presidencialistas latinoamericanos, sería plausible aplicar con cierta esperanza de éxito, cierto semipresidencialismo por estas latitudes.

Giovani Sartori, elogia el semipresidencialismo francés, mediante un catálogo de sus logros, para él éste ha evolucionado hasta convertirse en una estructura de verdadera condición mixta, dotado de flexibilidad que se hace patente en un mando estatal bifurcado o "bicéfalo”. En una expresión metafórica, el constitucionalista italiano afirma la capacidad oscilatoria del mando ejecutivo estatal que entra en dinámica con las combinaciones mayoritarias, las cuales si son de tipo unificado hacen destacar al Presidente con notoria hegemonía aplicándose por ende, la convenciones constitucionales; en el caso opuesto, al dividirse la mayoría, tal dinamismo colectivo pone al primer ministro sobre una especie de pedestal de mando, en cuya 
altura puede, mediante el apoyo del parlamento y la constitución formal ejecutar la pretensión de mando que le es propia.

Aunque un régimen de autoridad dual, debido a su intrínseca naturaleza puede paralizarse debido a un enfrentamiento emanado de un ejecutivo conflictuado, como podría acontecer al más granado de los ejemplos semipresidencialistas que perviven, no es posible dejar de reconocer que la problemática relativa a la división de las mayorías se ve soliviantada por lo que el autor del homo videns llama "cambio de cabeza"; es decir, la alternancia en el ejercicio del mando que detenta tanto la figura presidencial como la del primer ministro.

Si bien nosotros, hemos planteado a que pudiera el semipresidencialismo representar cierta esperanza de solución a un régimen político estancado, con cierto dejo de incredulidad; tal parece, que no es muy descabellado considerarlo dotado de cierta fuerza mágica, pues el mismo Sartori, ha tenido a bien llamarlo, no ingeniería, no sortilegio, sino "brillante, aunque involuntario acto brujería constitucional" ${ }^{34}$.

\section{FUENTES}

\section{BIBLIOGRAFIA}

ACOSTA ROMERO, Miguel, Teoría general del Derecho administrativo, ed., Porrúa, México, 1981.

DE GAULLE, Charles, Memorias de la guerra, la salvación, Editorial G., P., España, 1970 .

DUVERGER, Maurice; Instituciones politicas y derecho constitucional, Barcelona, Ariel, 1984.

, "A new political system model: semi-presidential government", en fournal of political research, vol. 8, núm. 2, 1980.

EBRAD CASAUBÓN, Marcelo y Robles Villaseñor, Mara, Semipresidencialismo en México, ¿salida al estancamiento del régimen?, Escuela de Administración Pública del Distrito Federal, México, 2011.

\footnotetext{
${ }^{34}$ Ibidem, p. 141.
} 
REIS NOVAIS, Jorge, Semipresidencialismo, teoría do sistema de governo semipresidencial, editorial Almedina, Portugal, 2007.

SARTORI, Giovanni; Ingeniería constitucional comparada, México, Fondo de Cultura Económica, 1994.

SEARA VAZQUEZ, Modesto, Las naciones unidas a los cincuenta años, FCE, México, 1995.

SHUGART, M. S. y Carey, J. M.; Presidents and Assemblies: Constitutional Design and Electoral Dynamics, Cambridge University Press, Nueva York, 1992. 
